\title{
Unraveling sources of stimulus control in a temporal discrimination task
}

\author{
Carlos Pinto $^{1}$ (D) Armando Machado ${ }^{1}$
}

Published online: 28 June 2016

(C) Psychonomic Society, Inc. 2016

\begin{abstract}
In temporal discriminations tasks, more than one stimulus may function as a time marker. We studied two of them in a matching-to-sample task, the sample keylight and the houselight that signaled the intertrial interval (ITI). One group of pigeons learned a symmetrical matching-to-sample task with two samples ( $2 \mathrm{~s}$ or $18 \mathrm{~s}$ of a center keylight) and two comparisons (red and green side keys), whereas another group of pigeons learned an asymmetrical matching-to-sample task with three samples ( $2 \mathrm{~s}, 6 \mathrm{~s}$, and $18 \mathrm{~s})$ and two comparisons (red and green). In the asymmetrical task, 6-s and 18-s samples shared the same comparison. In a subsequent retention test, both groups showed a preference for the comparison associated with the longer samples, a result consistent with the hypothesis that pigeons based their choices on the duration elapsed since the offset of the houselight (i.e., sample duration + retention interval). Results from two no-sample tests further corroborated the importance of the ITI illumination as a time marker: When the ITI was illuminated, the proportion of choices correlated positively with the retention interval; when the ITI was darkened, choices fell to random levels. However, the absolute value of choice proportions suggested that the sample stimulus was also a time marker. How multiple stimuli acquire control over behavior and how they combine remains to be worked out.
\end{abstract}

Keywords Coding · Timing · Stimulus control · Many-to-one matching $\cdot$ Delayed matching-to-sample $\cdot$ Pigeon

Carlos Pinto

carlos.arop@gmail.com

School of Psychology, University of Minho, Campus de Gualtar, 4710 Braga, Portugal
In temporal discrimination tasks, animals learn to behave according to the duration of one of more stimulus intervals. However, it is not always clear which stimuli signal the onset or the offset of the timed interval - that is, which stimuli function as time markers. To illustrate, consider a matching-tosample task for pigeons. On each trial, a center keylight is illuminated for $2 \mathrm{~s}$ or $10 \mathrm{~s}$ (sample), and then the pigeon chooses between a green key and a red key (comparisons), with green correct after the 2-s sample, and red after the 10-s sample. Researchers usually assume that sample onset and offset mark, respectively, the beginning and end of the duration that controls the pigeon's choices. However, stimuli that precede the trial may also influence the birds' performance. To illustrate, when the intertrial interval (ITI) is constant, the interval from the ITI onset to the sample offset (ITI + sample) could also be a discriminative stimulus for choice. In the same vein, because the end of the ITI and the beginning of the sample occur simultaneously, any of the two events may be used as a time marker.

The influence of the ITI may be revealed by inserting a retention interval between sample and comparisons. When the ITI and the retention interval are physically similar, pigeons' preference for the comparison associated with the shortest sample increases with the retention interval, the choose-short effect (e.g., Grant \& Spetch, 1993; Spetch \& Wilkie, 1982, 1983). But when the ITI and the retention interval are dissimilar, the choose-short effect usually is either weakened or eliminated (Pinto \& Machado, 2011; Sherburne, Zentall, \& Kaiser, 1998; cf. Kelly \& Spetch, 2000). The events that precede the trial influence how the pigeon responds to the sample duration.

In the same vein, changing the ITI duration also can affect choice in temporal discrimination tasks. Spetch and Rusak (1989) found that, when tested with ITIs shorter than in training, pigeons were biased toward the "long" comparison; when 
tested with ITIs longer than in training, they were biased toward the "short" comparison (see also Spetch \& Rusak, 1992). These examples further attest that performance in temporal discrimination tasks may depend on stimuli other than the sample.

Even studies not directly concerned with time markers have shown the influence of the ITI on temporal discrimination. Pinto and Machado (2015) were interested in pigeons' coding strategies in asymmetrical matching-to-sample tasks. During training, the pigeons learned to map three samples $(2 \mathrm{~s}$, $6 \mathrm{~s}$, and $18 \mathrm{~s}$ ) onto two comparisons (red and green hues) such that one comparison - for example, Red - was correct following the 2-s samples and the other comparison, Green, was correct following both the 6-s and 18-s samples. The aim was to test whether the pigeons' performance accorded to a single-code/default rule, a single code for the 2-s sample, and a default rule for all other samples (see also Clement \& Zentall, 2000; Singer, Klein, \& Zentall, 2006). Because the single code would be triggered by the shortest sample, mapped to Red, the default response rule would be triggered whenever the sample was not 2-s long, that is, "not short," and it would involve the choice of Green, the correct choice following the 6-s and 18-s samples. In sum, the single-code/default rule would be "If $2 \mathrm{~s}$, choose Red; otherwise, choose Green." The rule predicts that during a retention interval, as sample information is increasingly likely to be forgotten, the pigeons are more likely to use the default rule and therefore choose the "long" comparison - a choose-long effect. When Pinto and Machado introduced retention intervals ranging from $2.5 \mathrm{~s}$ to $20 \mathrm{~s}$, the pigeons showed a preference for the "long" comparison after all retention intervals.

Although the result is consistent with a single-code/default strategy, it is also consistent with the hypothesis that, instead of the sample onset, the stimulus signaling the end of the ITI functioned as the effective time marker. In Pinto and Machado's (2015) experiment, the 30-s ITI was illuminated by the houselight, the sample was the center keylight, and the retention interval was spent in darkness. During training, the end of the ITI, signaled by the houselight offset, and the start of the sample, signaled by the center keylight onset, occurred simultaneously. The same was true for the sample offset, signaled by the center keylight offset, and the comparisons onset, signaled by the onset of the red and green keylights. If the pigeons used the houselight offset $^{1}$ to initiate timing, perhaps because the houselight is more salient than the center keylight, they could have timed the interval from the houselight offset until the comparisons onset. Because this interval equals the sample duration during training, we cannot tell which time

\footnotetext{
${ }^{1}$ The animals could be timing the interval since the houselight was turned on (start of the 30-s ITI) or turned off (end of the ITI). Seeing that durations since houselight onset would be harder to discriminate ( $32 \mathrm{~s} \mathrm{vs.} 36 \mathrm{~s}$ vs. $48 \mathrm{~s}$ ) than durations since houselight offset ( $2 \mathrm{~s}$ vs. $6 \mathrm{~s}$ vs. $18 \mathrm{~s}$ ), we assumed that houselight offset was the time marker most likely to be used.
}

marker is effectively being used. However, on trials with retention intervals, the effectively timed durations should increase, and therefore the pigeons should prefer the "long" comparison, the observed choose-long effect (see bottom panel of Fig. 1, Time since ITI $>$ Sample duration).

This alternative account is also consistent with the results obtained in studies on the timing of empty intervals, that is, intervals signalled by brief start and stop markers (Grant, 2001; Grant \& Talarico, 2004; Santi, Hornyak, \& Miki, 2003; Santi, Ross, Coppa, \& Coyle, 1999). In these studies, the subjects seem to add the retention interval to the sample stimulus, leading to a "long"-key bias.

Identifying the exact time marker is relevant to the study of coding because it clarifies the sources of information an animal uses to establish its response rules. Additionally, knowing which stimulus is being used can change how researchers interpret the results of common tests. For instance, the interpretation of a retention test result changes if an animal is timing the duration of the sample stimulus or the duration of the interval since the end of the ITI. In the former case, the sample and retention interval durations remain different and separate; in the latter case, the sample and retention interval durations are added.

In this work, we aimed to clarify which stimuli control responding when multiple stimuli can be used as time markers (as is true for many timing tasks). To that end, one group of pigeons learned a task with two samples ( $2 \mathrm{~s}$ and $18 \mathrm{~s}$ ) and two comparisons (red and green hues), a task that should not induce a single-code/default strategy (see Grant \& Spetch, 1994). Afterward, these pigeons ran a series of retention test trials. In the absence of a single-code/default strategy, performance on retention trials should reveal the time marker that stopped timing. If the pigeons used the onset of the comparisons as the end of the to-be-timed interval, they would effectively be timing an empty interval with length "sample duration + retention interval." Hence, on test trials, we would expect preference for the "long" key to increase with the retention interval. On the other hand, if the sample offset was the "stop" time marker, and because no default "long" response rule was acquired, we would expect preference for the "short" key to increase with the retention interval (choose-short effect), or indifference between the two comparisons (Sherburne et al., 1998). As a replication, a second group of pigeons learned the same task as Pinto and Machado (2015), with three samples (2 s, $6 \mathrm{~s}$, and $18 \mathrm{~s}$ ) and two comparisons (red and green hues). After the retention tests, the two groups of pigeons switched tasks to determine whether differences in training could result in differences in coding that would affect performance on the tasks.

Finally, to identify the stimulus used as the "start" time marker-houselight offset or sample onset-we ran two retention-interval tests without the sample, one with a houselight-illuminated ITI and one with a dark ITI. In the first test, if the houselight was irrelevant and the sample was the 


\section{Training}

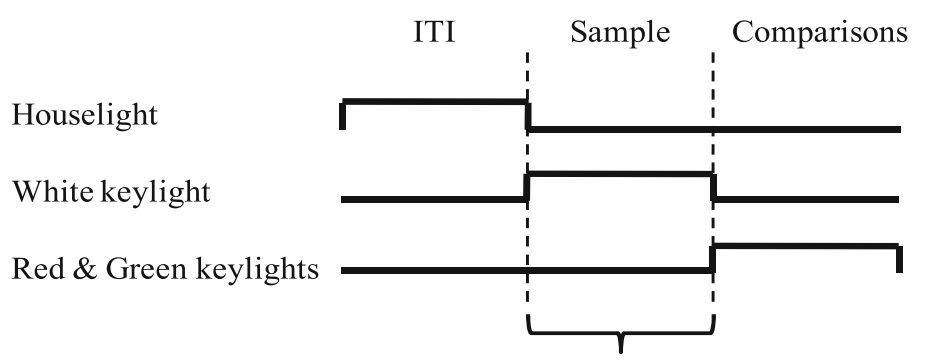

Sample duration

Time since ITI

\section{Retention Test}

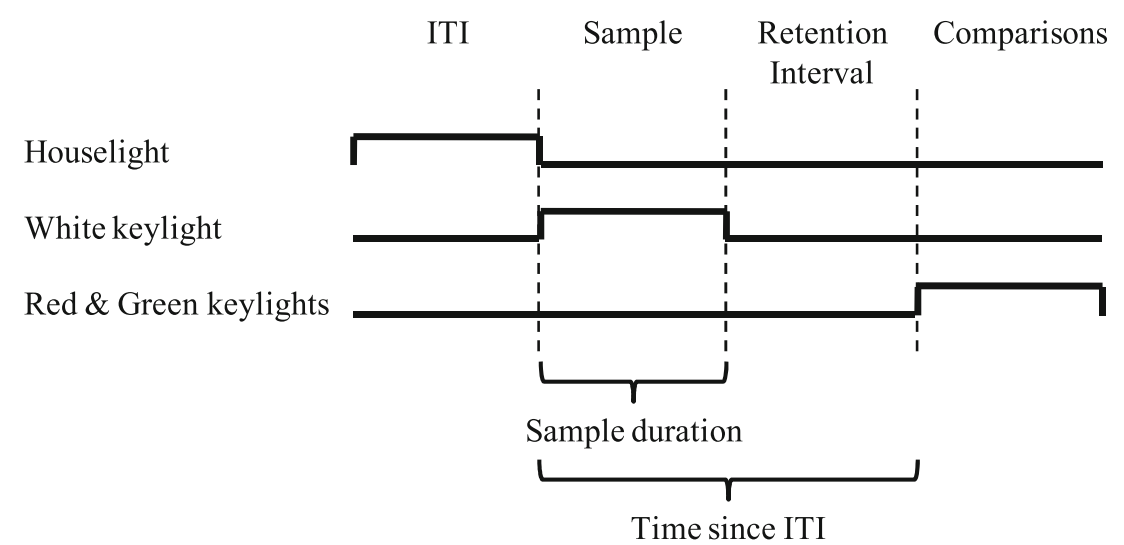

Fig. 1 Schematic of the stimuli presented during a trial in training (top panel) and retention tests (bottom panel). Each line is raised whenever its corresponding stimulus was turned on

main source of stimulus control, then, absent the sample, preference should not vary with the retention interval. The pigeons could show a bias for one comparison, but the bias should not change with the retention interval. Alternatively, if the pigeons learned to time the interval since houselight offset, preference for the "long" key should increase with retention interval. In the test with the dark ITI, without the two main sources of stimulus control, the pigeon was left without any cue about the appropriate choice. Hence, we expected indifference. Because the two no-sample tests differed only in the presence or absence of the houselight during the ITI, by contrasting the two test results we can assess the importance of the houselight on the animals' performance. The results from the various tests may help to unravel the sources of temporal control in a widely used temporal discrimination task.

\section{Method}

\section{Subjects}

Eight pigeons (Columba livia) were maintained at approximately $80 \%$ of their free-feeding body weight, with water and grit freely available in their home cages. The pigeon room was maintained in a 13:11 hour light/dark cycle, with lights on at 08:00, and its temperature was maintained between $20^{\circ} \mathrm{C}$ and $22^{\circ} \mathrm{C}$. The experiment was conducted once a day, 7 days a week, at approximately the same time of day for each pigeon. Three of the pigeons were experimentally naïve, and the remaining five had experience with timing tasks, either fixed interval schedules (Pinto, Fortes, Jozefowiez, \& Machado, 2012) or matching-to-sample tasks with temporal samples (Carvalho \& Machado, 2012).

\section{Apparatus}

Five LVE (Lehigh Valley Electronics) and a homemade chamber were used. The LVE chambers measured $34 \times 35 \times 31 \mathrm{~cm}$ $(\mathrm{h} \times 1 \times \mathrm{w})$. Three circular response keys, $2.5 \mathrm{~cm}$ in diameter, were arranged horizontally on the response panel, $9 \mathrm{~cm}$ apart, center to center. The bottom of each key was $22.5 \mathrm{~cm}$ above the wire mesh floor. Behind each key was a 12-stimulus IEE (Industrial Electronics Engineers) in-line projector. On the wall opposite the response panel, $30 \mathrm{~cm}$ above the floor, a 28-V, 0.1-A houselight provided general illumination. The 
food hopper was accessible through a $6-\mathrm{cm}$ wide $\times 5-\mathrm{cm}$ high opening on the response panel, centered horizontally, $8.5 \mathrm{~cm}$ above the floor. When the hopper was raised to provide grain to the pigeon, a 28-V, 0.04-A light illuminated its opening. The operant chamber was enclosed in an outer box equipped with an exhaust fan.

The homemade chamber measured $31 \times 33 \times 33 \mathrm{~cm}(\mathrm{~h} \times 1 \times$ w). Three circular response keys, $2.5 \mathrm{~cm}$ in diameter and $9 \mathrm{~cm}$ apart (center to center) were arranged horizontally on the response panel. The bottom edge of each key was $21 \mathrm{~cm}$ above the wire mesh floor. For the presentation of stimuli, a 12stimulus IEE (Industrial Electronics Engineers) in-line projector was installed behind each key. A LVE food hopper was accessible through a 6 -cm wide $\times 4.5-\mathrm{cm}$ high opening that was centered horizontally on the response panel, $6.5 \mathrm{~cm}$ above the floor. When the hopper was raised, a 28-V, 0.04-A light illuminated its opening. On the wall opposite the response panel, $27.5 \mathrm{~cm}$ above the floor, a 28-V, 0.1-A houselight provided general illumination. The operant chamber was enclosed by a PVC sound attenuating cubicle (Med Associates, ENV018V) equipped with an exhaust fan.

In this experiment, the side keys were illuminated with red or green hues, and the central key was illuminated with a white hue. Personal computers using the ABET II software (Lafayette Instrument Company) controlled the experimental events and recorded the data.

\section{Procedure}

Training I The animals were divided in two groups that learned two symbolic matching-to-sample tasks in different orders, a task with two samples ( $2 \mathrm{~s}$ and $18 \mathrm{~s}$ ), and a task with three samples ( $2 \mathrm{~s}, 6 \mathrm{~s}$, and $18 \mathrm{~s})$. A trial began with the illumination of the center key with white light for 2,6 , or $18 \mathrm{~s}$. At the end of the sample, the center keylight was turned off and the side keys were turned on, one with red and the other with green light. One comparison was correct following the 2-s sample, and the other comparison was correct following both 6-s and 18-s samples (the correct comparison for each sample was counterbalanced across pigeons). One peck at a comparison turned both keylights off. If the choice was correct, the pigeon had access to mixed grain and then the ITI started; if the choice was incorrect, the ITI started immediately. The ITI was illuminated with the houselight and lasted $30 \mathrm{~s}$. Throughout the experiment, the houselight was illuminated only during the ITI.

When a response was incorrect, the trial repeated (correction procedure); following three consecutive incorrect responses, only the correct comparison was presented. Excluding correction trials, a session comprised 64 trials. For the two-sample group, there were thirty-two 2-s sample trials and thirty-two 18 -s sample trials, and for the three-sample group, there were thirty-two 2-s sample trials, sixteen 6-s sample trials, and sixteen 18-s sample trials. That is, the number of times each comparison was correct was the same for all birds. The location of the comparison stimuli varied randomly across trials, with the constraint that each comparison occurred the same number of times on the left and right keys at the end of each session.

Training I continued for a minimum of 15 sessions and until the pigeons reached a criterion of at least $80 \%$ correct responses following each sample (excluding correction trials) for five consecutive sessions, or 25 sessions had elapsed, whichever occurred first. The birds began each session at approximately $80 \%$ of their free-feeding weight and the reinforcement duration, which was adjusted for each bird to minimize feeding outside the experimental session, varied from $3 \mathrm{~s}$ to $5 \mathrm{~s}$ across animals.

Retention test I In this phase, a retention interval was introduced between sample offset and comparison onset. Table 1 summarizes the session structure for both groups. The retention interval could be 2.5-, 5-, 10-, or 20-s long, and it was spent in darkness. A session comprised 80 trials. For the twosample group, there were 48 regular training trials ( 24 of $2 \mathrm{~s}$, 24 of $18 \mathrm{~s}$ ) and 32 retention-interval test trials (16 following each sample, four for each retention interval duration). For the three-sample group there were 48 regular training trials (24 of $2 \mathrm{~s}, 12$ of $6 \mathrm{~s}, 12$ of $18 \mathrm{~s}$ ) and 32 retention-interval test trials (16 following the 2-s sample, four per interval duration, and eight following the 6-s and 18-s samples, two per interval duration).

A correct response was always reinforced (both during training and test trials), but the correction procedure was in effect only on regular trials. To minimize extrasession feeding,

Table 1 Structure of retention test sessions for 2-sample and 3-sample groups

\begin{tabular}{llllll}
\hline & Retention Interval & \multicolumn{2}{l}{ Sample duration } & \multirow{2}{*}{ Total } \\
\cline { 3 - 5 } & & $2 \mathrm{~s}$ & $6 \mathrm{~s}$ & $18 \mathrm{~s}$ & \\
\cline { 3 - 5 } 2-sample group & $0 \mathrm{~s}$ & 24 & 0 & 24 & 48 \\
& $2.5 \mathrm{~s}$ & 4 & 0 & 4 & 8 \\
& $5 \mathrm{~s}$ & 4 & 0 & 4 & 8 \\
& $10 \mathrm{~s}$ & 4 & 0 & 4 & 8 \\
& $20 \mathrm{~s}$ & 4 & 0 & 4 & 8 \\
& Total & 40 & 0 & 40 & 80 \\
& $0 \mathrm{~s}$ & 24 & 12 & 12 & 48 \\
& $2.5 \mathrm{~s}$ & 4 & 2 & 2 & 8 \\
& $5 \mathrm{~s}$ & 4 & 2 & 2 & 8 \\
& $10 \mathrm{~s}$ & 4 & 2 & 2 & 8 \\
& $20 \mathrm{~s}$ & 4 & 2 & 2 & 8 \\
& Total & 40 & 20 & 20 & 80 \\
\hline
\end{tabular}


the reinforcement durations were readjusted and varied from $3 \mathrm{~s}$ to $5 \mathrm{~s}$ across animals. This phase lasted five sessions.

Training II Training II was the same as Training I with the exception that the tasks were reversed: The group that initially learned the two-sample discrimination now learned the threesample discrimination and vice versa. Reinforcement durations were recalculated and varied from $2.5 \mathrm{~s}$ to $7 \mathrm{~s}$ across animals.

Retention test II This phase was similar to Retention Test I, but with a different number of samples. That is, a pigeon that on Retention Test I ran the two-sample task now ran the threesample task, and vice versa. Reinforcement durations were recalculated and varied from $2.5 \mathrm{~s}$ to $5 \mathrm{~s}$ across animals.

Retraining I To re-establish a common, baseline performance before the no-sample tests, all pigeons returned to the threesample discrimination task. The stability criterion remained the same as before.

Lit ITI, no-sample retention test In this phase, no-sample trials were interspersed among regular training trials. In a nosample trial, after the ITI elapsed the houselight was turned off and, following an interval, the comparison keys were presented. This interval, spent with all lights off, could be 0 -s long (the comparison keys were presented immediately after the ITI), 2.5-, 5-, 10-, or 20-s long, in which case it was identical to the retention interval used in previous phases.

Each session comprised 78 trials, 48 regular training trials ( 24 of 2 s, 12 of 6 s, 12 of 18 s) and 30 no-sample trials (six trials $\times$ five retention intervals). No-sample trials were never reinforced. Reinforcement durations on regular trials were recalculated and varied from $2.5 \mathrm{~s}$ to $4 \mathrm{~s}$ across animals. Testing lasted 10 sessions.

Retraining II This phase was exactly the same as Retraining I, with the sole exception that, as soon as the performance criterion was met for two sessions, the pigeon moved to the next phase.

Dark ITI, no-sample retention test This test was the same as the no-sample retention test, with one exception: The ITI before no-sample trials was not illuminated. Therefore, before a no-sample trial began, the box was in darkness for the duration of the ITI, and continued dark for the duration of the retention interval in the no-sample trial, until the comparison keys were turned on. Reinforcement durations on regular trials varied from $2.5 \mathrm{~s}$ to $5 \mathrm{~s}$.

\section{Results}

\section{Training (I and II) \& retraining (I and II)}

The birds learning the two-sample task first needed from 15 to 18 sessions $(\bar{x}=16)$ to reach the criterion. Two of the four birds learning the three-sample task first needed 18 and 23 sessions, but the other two birds did not reach the criterion after 25 sessions. Although percentage correct fluctuated across sessions, both birds performed significantly above chance: For each sample, the average percentage of correct responses over the last five sessions was greater than $80 \%$.

The birds needed from 15 to 22 sessions $(\bar{x}=17)$ to reach criterion on the second task. Similarly, they needed from 15 to 23 sessions $(\bar{x}=16)$ to complete Retraining I, and from two to five sessions $(\bar{x}=3)$ to complete Retraining II.

\section{Retention tests (I and II)}

Figure 2 shows the results of the two retention tests, Test I on the left panel and Test II on the right panel. Each row of panels refers to the same pigeons, those who learned the two-sample task first (top) and those who learned the three-sample task first (bottom).

Consider the results of the Retention Test I (left panels). Both groups showed the same pattern: As the retention interval increased, correct responses following 2-s samples decreased, while correct responses following the 6-s and 18-s samples remained high. For the two-sample group (top left panel), a two-way repeated-measures ANOVA with sample duration (two levels) and retention interval (five levels) as factors revealed a significant main effect of sample duration, $F(1,3)=18.8, p=.023, \eta_{\mathrm{G}}^{2}=.72$, and of retention interval, $F(4,12)=26.60, p<.001, \eta_{\mathrm{G}}^{2}=.69$. The interaction also was significant, $F(4,12)=8.73, p=.002, \eta_{\mathrm{G}}^{2}=.47$, confirming that matching accuracy following the two samples was affected differently by the retention interval. Moreover, average percentage correct following the 2-s samples on retentioninterval trials was significantly below $50 \%, 95 \%$ CI [32.5\%, $43.1 \%]$.

For the three-sample group (bottom left panel), a $3 \times 5$ repeated-measures ANOVA showed a significant main effect of sample duration, $F(2,6)=27.93, p=.001, \eta_{\mathrm{G}}^{2}=.81$, retention interval, $F(4,12)=16.54, p<.001, \eta_{\mathrm{G}}^{2}=.43$, and their interaction, $F(8,24)=14.62, p<.001, \eta_{\mathrm{G}}^{2}=.57$, confirming that the effect of the retention interval was not the same for all samples. Similarly to the two-sample group, percentage correct following 2-s samples on retention-interval trials was significantly below chance, $95 \%$ CI [22.9\%, $32.7 \%]$.

Consider the Retention Test II (see Fig. 2, right panels). We found a similar pattern to Retention Test I: With the retention interval, performance following 2-s samples decreased below chance, whereas performance following the 6-s and 18-s 
Retention Test I

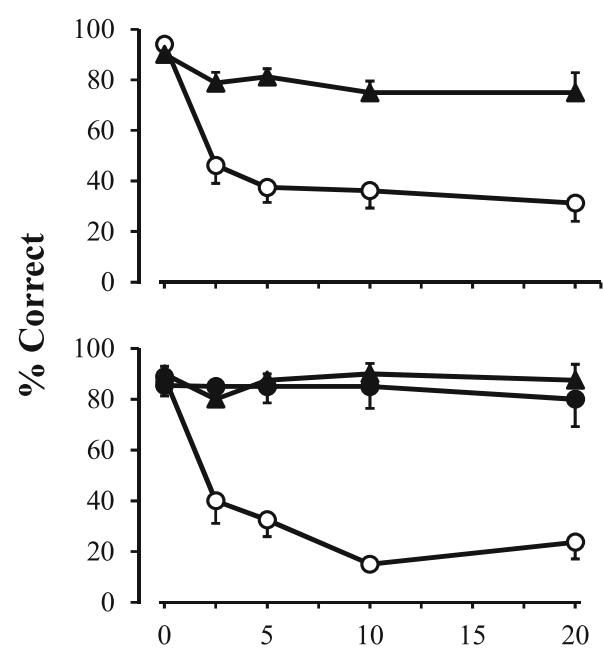

Retention Test II

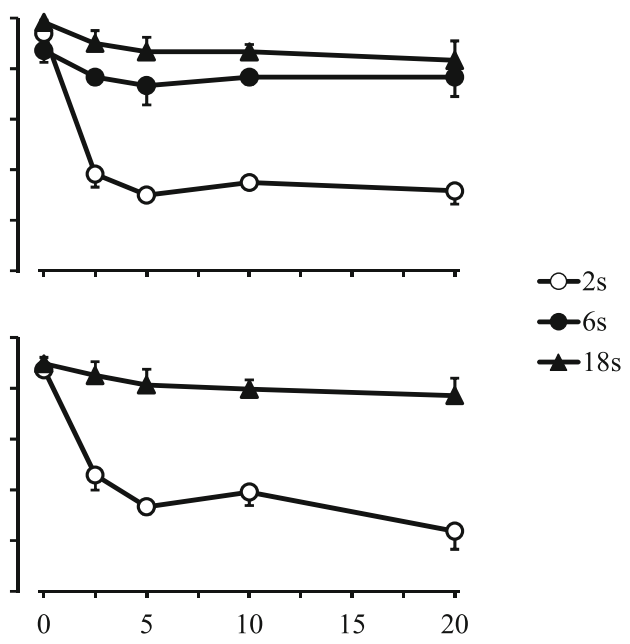

Retention Interval (s)

Fig. 2 Mean (with $S E M$ ) percentage correct to each sample duration as a function of retention interval duration. The panels on the left refer to Retention Test I and the panels on the right refer to Retention Test II. The panels on the top refer to the group of pigeons that first learned the

samples remained high. Therefore, the pattern of choices in Retention Test I was maintained in Retention Test II. For the group with three samples (top right panel), this reading was confirmed by a $3 \times 5$ repeated-measures ANOVA, which showed a significant effect of sample duration, $F(2,6)=$ $21.01, p=.002, \eta_{\mathrm{G}}^{2}=.79$, retention interval, $F(4,12)=59.87$, $p<.001, \eta_{\mathrm{G}}^{2}=.53$, and their interaction, $F(8,24)=7.85, p<$ $.001, \eta_{G}^{2}=.49$. Percentage correct following 2-s samples on retention-interval trials was significantly below $50 \%, 95 \%$ CI $[21.4 \%, 31.1 \%]$.

Regarding the group with two samples (bottom right panel), a $2 \times 5$ repeated-measures ANOVA revealed a significant main effect of sample duration, $F(1,3)=86.14, p=.003$, $\eta_{\mathrm{G}}^{2}=.81$, retention interval, $F(4,12)=14.59, p<.001$, $\eta_{\mathrm{G}}^{2}=.68$, and their interaction, $F(4,12)=9.75, p=.001$, $\eta_{\mathrm{G}}^{2}=.50$, once again confirming the differential effect of retention interval following the two samples. Percentage correct following 2-s samples on retention-interval trials was significantly below chance, $95 \%$ CI [30.4\%, $40.9 \%$ ].

\section{No-sample retention tests with lit and dark ITI}

Although all pigeons went through the same baseline condition with three-samples before the no-sample tests, they had different histories. Hence, we first compared performance on the no-sample test as a function of group. A repeatedmeasures ANOVA with one between-subjects factor (group) and one within-subjects factor (retention interval) showed no significant effect of group, $F(1,6)=.026, p=.876, \eta_{\mathrm{G}}^{2}=.003$, or factor interaction, $F(4,24)=.694, p=.603, \eta_{\mathrm{G}}^{2}=.03$, confirming that differences in learning history were not task with two samples and then learned the task with three samples. The panels on the bottom refer to the group of pigeons that learned the tasks in reverse order

affecting performance on this task. Therefore, data from all animals were collapsed and analyzed together.

The empty circles in Fig. 3 show the result of the Lit ITI, No-sample Test. On trials without a retention interval, the pigeons preferred the "short" key. A $t$ test confirmed that this preference was significantly different from $50 \%, t(7)=$ $3.99, p=.005, d_{z}=1.41$. On trials with retention intervals, the preference shifted toward the "long" key. A one-way repeated-measures ANOVA revealed a significant main effect of the retention interval, $F(4,28)=18.93, p=.001$, $\eta_{\mathrm{G}}^{2}=.46$. By the 20 -s retention interval, the preference for the "long" key was significantly above indifference: $t(7)=2.85$, $p=.025, d_{z}=1.01$.

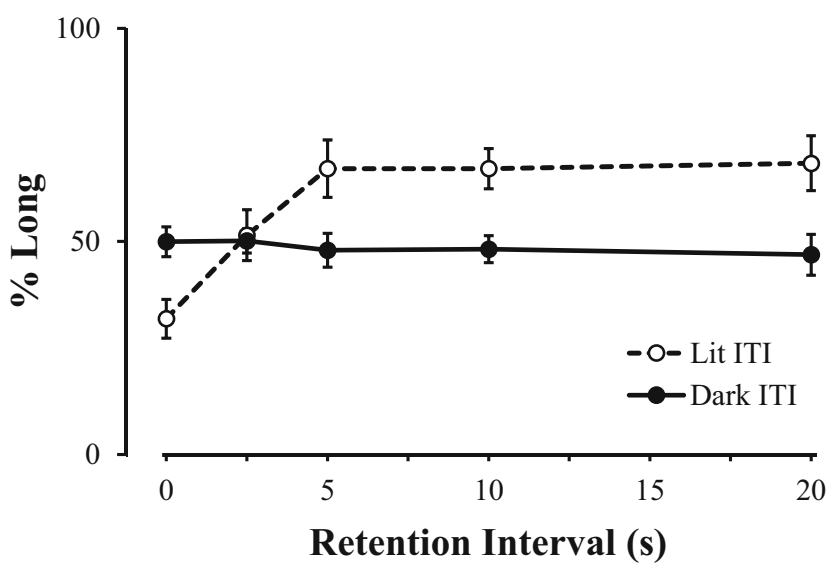

Fig. 3 Mean (with $S E M$ ) percentage of choices to the "long" key (associated with 6-s and 18-s samples) as a function of retention interval on the Lit ITI, No-sample Retention Test (empty circles) and on the Dark ITI, No-sample Retention Test (filled circles) 
The filled circles show the results from the Dark ITI, Nosample Retention Test. The pigeons were indifferent between the two comparison keys, and preference did not vary with the retention intervals. A one-way repeated-measures ANOVA showed no significant effect of retention interval, $F(4,28)=$ $.784, p=.545, \eta_{\mathrm{G}}^{2}=.02$. Additionally, choices were not significantly different from indifference, $95 \%$ CI [ $46.4 \%, 50.5 \%$ ].

\section{Discussion}

In this article we aimed to identify the "start" and "stop" time markers in a temporal discrimination task by using two types of tests, retention interval and no-sample tests. The retention interval tests examined which stimulus signalled the end of the duration that controlled the pigeons' choices. The birds were first divided in two groups, one that should have learned a single-code/default strategy to map three samples onto two comparisons, and one that should not (two samples and two comparisons). The three-sample group replicated Pinto and Machado's (2015) procedure and thereby checked the reliability of their findings. The results were similar, a strong preference for the "long" key (see Fig. 2, lower left panel). The other group tested the key idea: In the absence of a single-code/ default strategy, a strong preference for the "long" key would suggest the use of the comparisons onset as the "stop" time marker. Introducing the retention intervals would make the effectively timed interval longer, which would yield a strong preference for the "long" key. The results (Fig. 2, upper left panel) were consistent with the hypothesis.

Subsequently, the groups learned the other discrimination task and again ran retention interval tests. The preference functions in Retention Test II (Fig. 2, right panels) were consistent with the preference functions in Retention Test I (Fig. 2, left panels). Both showed a strong preference for the "long" key. The fact that the preferences remained the same on both sets of retention tests suggests that the order in which the tasks were learned did not affect the coding strategy.

The no-sample tests assessed which stimulus functioned as the "start" time marker. By removing the sample stimulus, we aimed to assess directly the role of the houselight offset as a time marker. If sample onset triggered timing, by removing the sample, timing should not take place, which should result in random responding. But if the houselight offset was the "start" time marker, we would expect choices to correlate with the retention interval: the longer the retention interval, the longer the interval since the ITI offset, and therefore the stronger the preference for the "long" key. The results from the Lit ITI, No-sample Retention Test (see Fig. 3, empty circles) were consistent with the latter prediction. Choices immediately following the ITI were mostly to the "short" key, but, as the retention interval increased, preference shifted towards the "long" key.
In the second no-sample test, the houselight remained off during the ITI. This manipulation complemented the Lit ITI, No-sample Test because, by comparing the two no-sample tests, we could assess how behavior was affected by the removal of the houselight. The results showed random choice across all retention intervals (Fig. 3, filled circles), a result distinctly different from the Lit ITI, No-sample Test. The change in performance occasioned by removing the houselight during the nosample tests shows clearly that the houselight influenced choice.

Taken together, the results of the no-sample tests lend further support to the hypothesis that the pigeons used the houselight offset as the "start" time marker. If choices were made exclusively on the basis of how much time had elapsed since the offset of the houselight, on no-sample trials choices would approach the values obtained during regular trials with comparable samples. However, that was not the case. The pigeons chose the "short" key $94 \%$ of the time on 2-s regular trials, but that preference fell to $49 \%$ on no-sample trials with a $2.5-\mathrm{s}$ retention interval. The same was true for longer values: the pigeons chose the "long" key $98 \%$ of the time on 18-s regular trials, but that preference fell to $68 \%$ on no-sample trials with a 20-s retention interval.

Performance worsened when the sample stimulus was removed and also when the ITI was darkened (by this point the pigeons were responding randomly). The fact that the removal of each of these stimuli had an effect on performance suggests that both controlled choice. This joint control can be seen in Fig. 4, where all average data were replotted as a function of time since the houselight offset. Each line represents a sample duration. If houselight offset were the only "start" time marker (i.e., the sample stimulus was irrelevant), the curves should overlap. The fact that they do not overlap shows that the sample also controlled choice.

Not all studies with illuminated ITIs and dark retention intervals have found a choose-long effect. For instance,

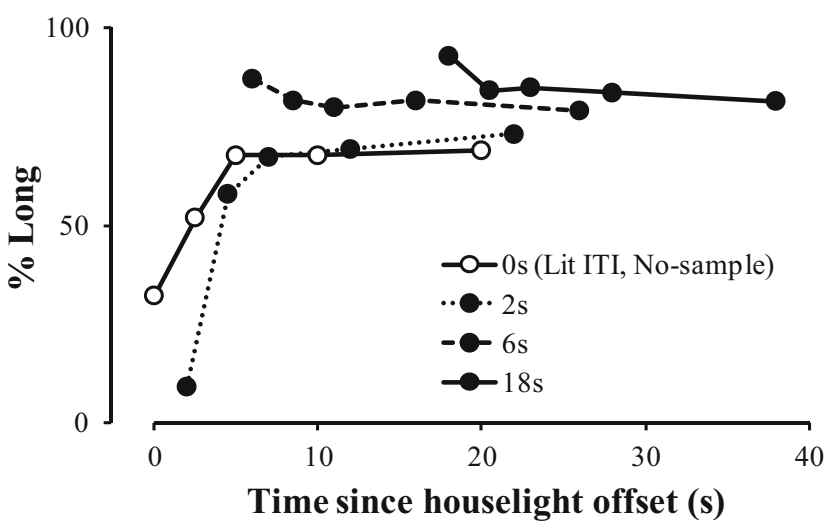

Fig. 4 Mean percentage of choices to the "long" key (associated with 6-s and 18-s samples) as a function of time since houselight offset. Each line refers to a sample duration. The filled circles represent the collapsed data from Retention Test I and II and the empty circles represent the data from the Lit ITI, No-sample Retention Test 
Sherburne et al. (1998) found that, on a retention test, matching accuracy did not differ between the two trained samples $(2 \mathrm{~s}$ and $10 \mathrm{~s})$. The reason for the different results may be related to the fact that in Sherburne et al. (1998) the 10-s ITI was considerably shorter than the 30 -s ITI used in the present experiment. Perhaps a shorter presentation of the houselight may have made it less likely to control choice. In another study, Kelly and Spetch (2000) obtained a bias toward the "short" key (choose-short effect) in a task that had a long ITI (45 s), but used a 5 -s retention interval during training. In another study that employed a retention interval during training (but with variable duration), a choose-long effect, similar to the one found in this paper, was obtained (Dorrance, Kaiser, \& Zentall, 2000). It is not entirely clear how task differences lead to distinct retention-test functions, but the variety of the results suggests that a houselightilluminated ITI per se does not make the houselight a time marker.

Another variable that influences the coding strategy adopted in a matching-to-sample task is the sample-comparison mapping. There has been some evidence that many-to-one mappings eliminate the choose-short effect (Grant \& Spetch, 1993; Santi, Bridson, \& Ducharme, 1993). However, in those studies, the choose-short effect was not replaced by the choose-long effect found in the present work, which reinforces the hypothesis that the preference for the "long" comparison we found was not due to the sample-comparison mapping, but to the influence of the ITI houselight.

This study shows that, in a temporal matching-to-sample task, other stimuli besides the sample may control responding. This result supplements previous research that has shown that more than one stimulus or event may be attended to and concurrently control responding (e.g., Cheng, Spetch, \& Miceli, 1996; Davison \& Elliffe, 2010; Roberts \& Mitchell, 1994; Shahan \& Podlesnik, 2006), and that animals are able to simultaneously time more than one interval (e.g., Kirkpatrick \& Church, 2000; Leak \& Gibbon, 1995; Meck \& Church, 1984). To understand how and what animals learn, even in simple temporal discrimination tasks, it is important to identify the multiple sources of stimulus control present in the task. In addition, we also need to identify the procedural features that occasion joint stimulus control and the determinants of the relative degree of stimulus control achieved by each source.

Acknowledgments This work was conducted at the Psychology Research Centre, University of Minho, and was supported by the Portuguese Foundation for Science and Technology (FCT) and the Portuguese Ministry of Education and Science through national funds, and when applicable co-financed by FEDER under the PT2020 Partnership Agreement (UID/PSI/01662/2013). This work was also supported by a FCT Doctoral Grant (SFRH/BD/78566/2011) to Carlos Pinto and a FCT Grant (PTDC/MHC-PCN/3540/2012) to Armando Machado.

\section{References}

Carvalho, M. P., \& Machado, A. (2012). Relative versus absolute stimulus control in the temporal bisection task. Journal of the Experimental Analysis of Behavior, 98, 23-44.

Cheng, K., Spetch, M. L., \& Miceli, P. (1996). Averaging temporal duration and spatial position. Journal of Experimental Psychology: Animal Behavior Processes, 22, 175-182.

Clement, T. S., \& Zentall, T. R. (2000). Development of a single-code/default coding strategy in pigeons. Psychological Science, 11, 261-264.

Davison, M., \& Elliffe, D. (2010). Divided stimulus control: A replication and a quantitative model. Journal of the Experimental Analysis of Behavior, 94, 13-23.

Dorrance, B. R., Kaiser, D. H., \& Zentall, T. R. (2000). Event-duration discrimination by pigeons: The choose-short effect may result from retention-test novelty. Animal Learning \& Behavior, 28, 344-353.

Grant, D. S. (2001). Memory for empty time intervals in pigeons. Animal Learning \& Behavior, 29, 293-301.

Grant, D. S., \& Spetch, M. L. (1993). Analogical and nonanalogical coding of samples differing in duration in a choice-matching task in pigeons. Journal of Experimental Psychology: Animal Behavior Processes, 19, 15-25.

Grant, D. S., \& Spetch, M. L. (1994). The role of asymmetrical coding of duration samples in producing the choose-short effect in pigeons. Learning and Motivation, 25, 413-430.

Grant, D. S., \& Talarico, D. C. (2004). Processing of empty and filled time intervals in pigeons. Learning \& Behavior, 32, 477-490.

Kelly, R., \& Spetch, M. L. (2000). Choice biases in delayed matching-tosample duration with pigeons: Manipulations of ITI and delay illumination. The Quarterly Journal of Experimental Psychology, 53B, 309-323.

Kirkpatrick, K., \& Church, R. M. (2000). Stimulus and temporal cues in classical conditioning. Journal of Experimental Psychology: Animal Behavior Processes, 26, 206-219.

Leak, T. M., \& Gibbon, J. (1995). Simultaneous timing of multiple intervals: Implications of the scalar property. Journal of Experimental Psychology: Animal Behavior Processes, 21, 3-19.

Meck, W. H., \& Church, R. M. (1984). Simultaneous temporal processing. Journal of Experimental Psychology: Animal Behavior Processes, 10, 1-29.

Pinto, C., Fortes, I., Jozefowiez, J., \& Machado, A. (2012). Interaction of temporal memories in extinction. In P. Guilhardi, M. Menez, \& F. López (Eds.), Tendencias en el estudio contemporáneo de la estimación temporal (pp. 193-222). Mexico City, Mexico: Universidad Nacional Autónoma de México.

Pinto, C., \& Machado, A. (2011). Short-term memory for temporal intervals: Contrasting explanations of the choose-short effect in pigeons. Learning and Motivation, 42, 13-25.

Pinto, C., \& Machado, A. (2015). Coding in pigeons: Multiple-coding versus single-code/default strategies. Journal of the Experimental Analysis of Behavior, 103, 472-483.

Roberts, W. A., \& Mitchell, S. (1994). Can a pigeon simultaneously process temporal and numerical information? Journal of Experimental Psychology: Animal Behavior Processes, 20, 66-78.

Santi, A., Bridson, S., \& Ducharme, M. (1993). Memory codes for temporal and nontemporal samples in many-to-one matching by pigeons. Animal Learning \& Behavior, 21, 120-130.

Santi, A., Hornyak, S., \& Miki, A. (2003). Pigeons' memory for empty and filled time intervals signaled by light. Learning and Motivation, 34, 282-302.

Santi, A., Ross, L., Coppa, R., \& Coyle, J. (1999). Pigeons' memory for empty time intervals marked by visual or auditory stimuli. Animal Learning \& Behavior, 27, 190-205.

Shahan, T., \& Podlesnik, C. (2006). Divided attention performance and the matching law. Learning \& Behavior, 34, 255-261. 
Sherburne, L. M., Zentall, T. R., \& Kaiser, D. H. (1998). Timing in pigeons: The choose-short effect may result from pigeons' "confusion" between delay and intertrial intervals. Psychonomic Bulletin \& Review, 5, 516-522.

Singer, R. A., Klein, E. D., \& Zentall, T. R. (2006). Use of a single-code/ default strategy by pigeons to acquire duration sample discriminations. Learning \& Behavior, 34, 340-347.

Spetch, M. L., \& Rusak, B. (1989). Pigeons' memory for event duration: Intertrial interval and delay effects. Animal Learning \& Behavior, $17,147-156$
Spetch, M. L., \& Rusak, B. (1992). Temporal context effects in pigeons' memory for event duration. Learning and Motivation, $23,117-144$.

Spetch, M. L., \& Wilkie, D. M. (1982). A systematic bias in pigeons' memory for food and light durations. Behaviour Analysis Letters, 2, 267-274.

Spetch, M. L., \& Wilkie, D. M. (1983). Subjective shortening: A model of pigeons' memory for event duration. Journal of Experimental Psychology: Animal Behavior Processes, 9, 14-30. 